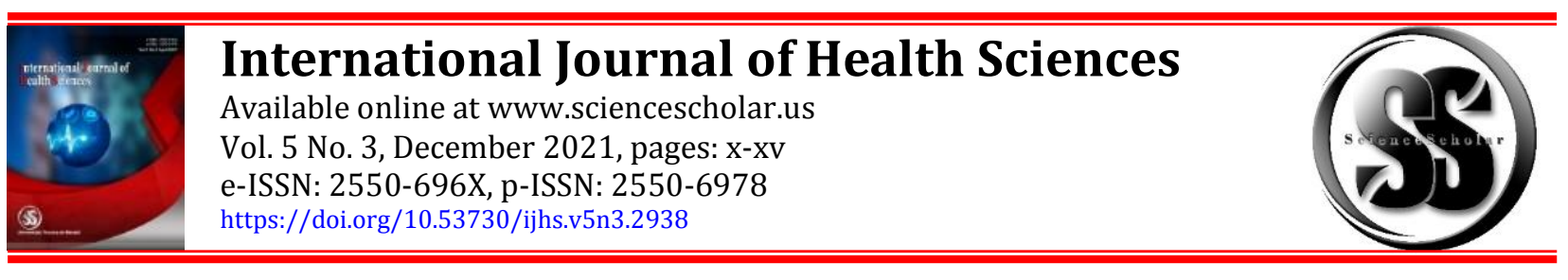

\title{
Get Vaccinated When it is Your Turn and Follow the Local Guidelines
}

\author{
(D) crossmark \\ I Wayan Suryasa a, María Rodríguez-Gámez ${ }^{\mathrm{b}}$, Tihnov Koldoris ${ }^{\mathrm{c}}$
}

\begin{tabular}{l} 
Editorial \\
\hline Keywords \\
basic health; \\
COVID-19; \\
health agencies; \\
health facilities; \\
health insurance; \\
health protocols; \\
health service; \\
universal health system; \\
vaccination;
\end{tabular}

Abstract

The nurse has an important role caring for the patient infected with the coronavirus disease (COVID-19). It is an infectious disease caused by the SARS$\mathrm{CoV}-2$ virus. The virus can spread from the mouth or nose of an infected person in small liquid particles when they cough, sneeze, speak, sing, or breathe. These particles range from larger respiratory droplets to smaller aerosols. It is important to practice respiratory etiquette, for example coughing into a flexed elbow, and to stay home and self-isolate until you recover if you feel unwell. Most people infected with the virus will experience mild to moderate respiratory illness and will recover without requiring special treatment. Older people and people with underlying medical conditions such as cardiovascular disease, diabetes, chronic respiratory disease, or cancer are more likely to develop serious illnesses. The goal of the research is to propose the best way to prevent and slow down transmission is to be well informed about the disease and how the virus spreads. Protect yourself and others from infection by staying at least 1 meter away from others, wearing a well-fitting mask, and washing your hands or using an alcohol-based rub frequently.

International Journal of Health Sciences (C) 2021. This is an open access article under the CC BY-NC-ND license (https://creativecommons.org/licenses/by-nc-nd/4.0/).

\section{Introduction}

Indonesian citizens' understanding of the COVID-19 vaccine program was summarized by Widjaja et al. (2021), where I state that it is both challenging like a hope. An appeal is needed from organizations not to oppose vaccination against COVID-19. For this vaccine to be effective in countering the COVID-19 disease, a proper understanding is needed, based on most people who still believe in the conspiratorial idea of the global elite that vaccines are being developed for the benefit of the pharmaceutical companies or to implant microchips in their bodies. The data from your study of residents in various regions requires a correct

a ITB STIKOM Bali, Denpasar, Indonesia

b Universidad Técnica de Manabí, Portoviejo, Ecuador

c Queen Mary University of London, London, United Kingdom 
understanding of the results of an in-depth study. Another challenge of the government is that the distribution of the vaccine logistics is not yet evenly distributed so that all citizens can quickly receive the vaccines with full understanding and support from medical professionals, both understanding and benefiting from the COVID-vaccine. 19, where in many cases through the networks people receive confusing information during the COVID-19 vaccine campaign.

The community care strategy for the family if the health of tourism during the COVID-19 pandemic is a top priority based on these criteria if health, family, and tourism are an iconic security in the provision of communication, the supervisors of information and education media (IEC) confirmed the prevention and control of COVID-19 in strategic locations, declared by (Asman et al., 2021). Achieve prevention in tourist attractions; inspection and direct surveillance within a specified period, if it is the family that carries out the activity; the community insurance socializes the health protocols that must be applied to the families that carry out tourist activities; evaluation of health service programs provided to families; coordination of innovation and collaboration of community contributions with local communities living around tourist sites; improve the quality and role of the community that receives the treatment of family supervisors in each tourist place; and the use of an emotional approach in the provision of health services to families (Uehara et al., 2001; Abou-Auda, 2003).

The overwhelming majority of experts, post-COVID syndrome is a mental disorder that is a kind of reaction to the COVID-19 pandemic, according to (Bocheliuk et al., 2021). This disorder has already affected $15 \%$ of the population. An acute stress response is increasingly seen in the context of the spread of infection and changes in the usual way of life. The most serious manifestations in its clinical picture are like post-traumatic stress disorder.

The danger of this syndrome is that it will continue to reduce the working capacity of the population at a time when it will be so important for the recovery of the economy. Generally, risk groups are considered medical professionals caring for COVID patients; people who have had a severe form of the disease; people who have lost family and friends; those who have suffered considerable financial loss or lost their jobs, and people of specific psychological types (McIntyre et al., 2020; Padwa et al., 2016).

The questions raised require more detailed research and development in both theoretical and practical areas. It is time to study the risk groups in more depth, based on the age, sex, personality and psychological affiliation of the people affected by the coronavirus infection. In short, it will be possible to objectively study the problem of the duration of post-COVID syndrome in people with different psychological qualities. Other aspects related to the problem of overcoming post-COVID symptoms by different categories of the population, despite the broad interest of researchers in them, require more attention due to their high degree of relevance (Pagan et al., 2006; Loewenstein et al., 2013).

Midwives must make careful preparations while providing birthing services in independent practice during the COVID-19 pandemic, considering that the risk of becoming infected to death is highly vulnerable to occur in this profession. COVID-19 related training and delivery services during the pandemic, financial support, health insurance and routine rapid test screening for midwives should be carried out and become a particular concern for all independent practices (Zulfa et al., 2021).

COVID-19 caused by the new coronavirus, represents a serious global threat to humans, which could escalate to a pandemic. It appears that kidney damage is common with this infection, and ARF is an independent predictor of mortality. The impact of this infection in patients with chronic kidney disease has not been studied, and dialysis patients suspected of having COVID-19 should be managed according to strict protocols to minimize the risk of transmission to other patients and the medical personnel caring for them these patients (Rahkmonova et al., 2021).

Urinov et al. (2021), found a moong examined patients with COVID-19, the gender index was 1.3: 1.0 in favor of men, a severe course of the disease was detected in 1.3\%, moderate - in $31.8 \%$, a mild course - at $48.9 \%$. Young people (especially women) were more common with mild disease (64.2\%), middle-aged, with moderate-severe COVID-19 (54.8\%). Elderly female patients predominated in the group of patients with severe coronavirus infection, and among middle-aged men: $47.8 \%$ and $48.4 \%$, respectively. According to this study, the comorbid background before COVID-19 disease and emerging neurological complications in the context of COVID-19, in percentage terms, prevailed in men. There were no significant differences in the incidence of complications from the severity of COVID-19 disease. At the time of hospitalization, all the studied markers of clotting activity were changed in the patients and statistically significantly deviated from

Suryasa, I. W., Rodríguez-Gámez, M., \& Koldoris, T. (2021). Get vaccinated when it is your turn and follow the local guidelines. International Journal of Health Sciences, 5(3). https://doi.org/10.53730/ijhs.v5n3.2938 
the reference interval, indicating the activation of the pro clotting potential. In the group of female patients, these indicators were more pronounced. The CT scan found that the percentage of damage to both lungs was significantly higher in women compared to men (Cho et al., 2008; Tobacco, 2008).

Social support in the form of family and peer support could become a means of increasing the OSH knowledge, attitude, and practice of limestone processing workers. The role of peer support was the job owners, while the family supporters were the workers' wives who informed and motivated the workers to apply K3. Based on the result, research can continue to compare the role of family support with peer support to discover the most important factor affecting the change in attitudes of workers (Sukismanto et al., 2021). There is a significant effect after doing the self-hypnosis therapy with positive self-talk on the stress level of the cooperative working group for the prevention of COVID-19. Doing self-hypnosis with positive self-talk can significantly reduce the stress levels of the COVID-19 prevention workgroup (Candra et al., 2021).

Suiraoka et al. (2021), completed the anthropometric examinations of 375 primary school children. It is known that $35.5 \%$ are overweight and $12.3 \%$ are obese. This figure is still above the prevalence of obesity in primary school children according to research basic health, 2018 (21.8\%). Consumption factors have the greatest contribution to increasing the risk of obesity. In the following order, other social factors emerged; Lifestyle; physical activity; followed by environmental factors.

In the final section, Manullang (2021), summarized reiterating that it aims to understand the legal basis for administering the COVID vaccine to Indonesian citizens. You think you have responded to the problem in this study with an understanding of the topic; compiled published research evidence from various journals that have a high level of investment in discussions of the legal point of administering vaccines to the public and many journals raising the issue of this COVID-19 outbreak.

Our data sources visit various well-known publications such as Elsevier, Sage pub, Google Books, Taylor and France, and other Indonesian publications. So, after collecting the data, continue the study involving the coding system, evaluating the data carefully, and then try to interpret it as much as possible to get an answer that we consider its validity and reliability.

The findings shown have been drawn from several existing literatures that, on average, say that each country has a transparent umbrella for implementing vaccination programs, all of which aim to combat the dangers of the COVID-19 outbreak in their respective citizens. However, its implementation also faces challenges and opportunities. The challenge remains that there are many citizens who are for and against this vaccination program (Heininger et al., 2003; Kunz, 2003). Therefore, following the guidelines of the WHO and other health agencies, each country must convince its citizens to accept this vaccine with pleasure, not by coercion and other witnesses. Everything must have a legal basis and certainty for justice and equity in obtaining vaccination services from the state.

The behavior of the vaccination process in Latin America and the Caribbean has had different visions, in some countries there have been economic difficulties to apply them, others have achieved a stable supply of vaccines, and some have managed to vaccinate their entire population with their own resources and development of its biotechnology industry.

In Argentina has prioritized the groups with the highest epidemiological risk, starting the immunization process over Health Personnel, as reported (Luzuriaga et. al., 2021), from the vaccination campaign, the drop in the average relative incidence of HP was significantly more pronounced compared to the general population. It is good to mention the analysis carried out by (Tejedor, 2021), where the Bloomberg COVID-19 resilience ranking is shown where a variety of data is analyzed to obtain a better understanding of where the pandemic is being managed in the most effective way, with the least social and economic disturbance, ranking the best and worst countries to pass the pandemic. On the one hand, this ranking classifies New Zealand, Singapore, and Australia as the three best countries to be in this pandemic; and we can observe countries such as Mexico, South Africa and Colombia rank as the worst places to be located in these pandemic times.

The case of Cuba was very special as it is a country with different policies than many countries in the area, according to Resende et al. (2021), its experiences can contribute to the strengthening of public and universal health systems, where it stood out the scope of multiplicity of strategies and actions implemented and the search for their coordination and articulation, highlighting the issue of the development of vaccines against COVID-19, having as sources interviewed, updated by media reports, institutional documents and published articles. 
In Ecuador, initially the political crises and socioeconomic inequalities that affected Ecuador before the arrival of the pandemic paved the way for the ravages caused by the new coronavirus in the country (Chauca, 2021). In 2021 a vaccination process began, becoming an essential protection tool to protect people, it is recommended that adults over 65 be considered one of the priority groups for the administration of the vaccine, as well as the staff of health, and other high priority sectors such as teachers and students among others (Changoluisa \& Guarate, 2021).

The current situation in Ecuador today is different, even though a year ago the country was in international publications due to the collapse of its health system; today it could be a worldwide example of a vaccination campaign (Bortman \& Mohpal, 2021), being the country that supplies the most daily doses. $77.4 \%$ of the population in Ecuador has agreed to the vaccination plan against COVID-19, 68.9\% of the population is fully vaccinated and the remaining $8.5 \%$ is partially vaccinated. On the other hand, $4.2 \%$ of the population has received a booster dose (Observatorio, 2021).

\section{Recommendation}

The editorial team advises the entire population to be vaccinated when it is their turn and to follow local guidelines, always exhorting personnel linked to health facilities to maintain personal safety to have their own protection, that of the family and society.

\section{Acknowledgments}

We would also like to express our gratitude to all the contributors, namely the authors, reviewers, and editors, who have made this issue possible. IJHS is currently accepting manuscripts for upcoming issues based on original qualitative or quantitative research that opens new areas of inquiry and investigation.

\section{References}

Abou-Auda, H. S. (2003). An economic assessment of the extent of medication use and wastage among families in Saudi Arabia and Arabian Gulf countries. Clinical therapeutics, 25(4), 1276-1292. https://doi.org/10.1016/S0149-2918(03)80083-8

Asman, A., Asman, A., \& Dewi, A. K. (2021). Community nursing strategies for tourism health families during COVID-19 pandemic. International Journal of Health Sciences, 5(3), 224-231. https://doi.org/10.53730/ijhs.v5n3.1449

Bocheliuk, VY, Spytska, LV, Mamicheva, OV, Panov, MS, \& Kordonets, VV (2021). Psychological characteristics of the course of post-COVID syndrome. International Journal of Health Sciences, 5(3), 276-285. https://doi.org/10.53730/ijhs.v5n3.1503

Bortman, M., \& Mohpal, A. (2021). Why Ecuador vaccinates its population faster than the rest of the world. Blogs World Bank.

Candra, I. W., Sumirta, I. N., \& Mustika, I. W. (2021). Effect of self-hypnosis therapy with positive self-talk on stress levels of COVID-19 mutual cooperation task force. International Journal of Health Sciences, 441-448. https://doi.org/10.53730/ijhs.v5n3.1802

Changoluisa, L.J., \& Guarate, Y.C. (2021). Perception of the Relatives of Older Adults regarding the Application of the Vaccine Against COVID-19 in the Community of Patutan, Cotopaxi Province. Knowledge Pole Multidisciplinary Scientific-Academic Magazine.

Chauca, R. (2021). La covid-19 en Ecuador: fragilidad política y precariedad de la salud pública. História, Ciências, Saúde-Manguinhos.

Cho, Y. I., Lee, S. Y. D., Arozullah, A. M., \& Crittenden, K. S. (2008). Effects of health literacy on health status and health service utilization amongst the elderly. Social science \& medicine, 66(8), 1809-1816. https://doi.org/10.1016/j.socscimed.2008.01.003

Heininger, U., Bachtiar, N. S., Bahri, P., Dana, A., Dodoo, A., Gidudu, J., \& Dos Santos, E. M. (2012). The concept of vaccination failure. Vaccine, 30(7), 1265-1268. https://doi.org/10.1016/j.vaccine.2011.12.048

Kunz, C. (2003). TBE vaccination and the Austrian experience. Vaccine, 21, S50-S55. https://doi.org/10.1016/S0264-410X(02)00813-7

Suryasa, I. W., Rodríguez-Gámez, M., \& Koldoris, T. (2021). Get vaccinated when it is your turn and follow the local guidelines. International Journal of Health Sciences, 5(3). https://doi.org/10.53730/ijhs.v5n3.2938 
Loewenstein, G., Friedman, J. Y., McGill, B., Ahmad, S., Linck, S., Sinkula, S., ... \& Volpp, K. G. (2013). Consumers' misunderstanding of health insurance. Journal of Health Economics,32(5), 850-862. https://doi.org/10.1016/j.jhealeco.2013.04.004

Luzuriaga, J. P., Marsico, F., Garcia, E., González, V., Kreplak, N., Pifano, M., \& González, S. (2021). Impact of vaccines against COVID-19 on the incidence of new SARS-COV2 infections in health care workers of the Province of Buenos Aires. In Impact of vaccines against COVID-19 on the incidence of new SARS-COV2 infections in health care workers of the Province of Buenos Aires.

Manullang, S. O. (2021). Giving COVID-19 vaccines to citizens: Understanding legal basis. International Journal of Health Sciences, 364-372. https://doi.org/10.53730/ijhs.v5n3.1598

McIntyre, H. D., Gibbons, K. S., Ma, R. C., Tam, W. H., Sacks, D. A., Lowe, J., ... \& Catalano, P. M. (2020). Testing for gestational diabetes during the COVID-19 pandemic. An evaluation of proposed protocols for the United Kingdom, Canada and Australia. diabetes research and clinical practice, 167, 108353. https://doi.org/10.1016/j.diabres.2020.108353

Padwa, H., Teruya, C., Tran, E., Lovinger, K., Antonini, V. P., Overholt, C., \& Urada, D. (2016). The implementation of integrated behavioral health protocols in primary care settings in project care. Journal of Substance Abuse Treatment, 62, 74-83. https://doi.org/10.1016/j.jsat.2015.10.002

Pagan, J. A., Ross, S., Yau, J., \& Polsky, D. (2006). Self-medication and health insurance coverage in Mexico. Health policy, 75(2), 170-177. https://doi.org/10.1016/j.healthpol.2005.03.007

Rahkmonova, S., Khaytboyev, J., Zargarova, N., Otajonova, D., \& Kazakov, K. (2021). Kidney complications after COVID-19. International Journal of Health Sciences, 393-402. https://doi.org/10.53730/ijhs.v5n3.1698

Resende, S., Santos, A .; Freitas, C., Modolo. L., Tenório, G. (2021). The public-universal health systems and the Cuban experience in the face of the COVID-19 pandemic. Interviews Interface (Botucatu)

Social Observatory of Ecuador (2021). Monitoring of the COVID-19 coronavirus in Ecuador.

Suiraoka, I.P., Nursanyoto, H., \& Suastiti, N.M.A. (2021). Determinant of childhood obesity in the COVID-19 pandemic and intervention requirement analysis. International Journal of Health Sciences, 5(3), 503-512. https://doi.org/10.53730/ijhs.v5n3.2116

Sukismanto, S., Hartono, H., Sumardiyono, S., \& Andayani, T.R. (2021). Social support role of the implementation of occupational safety and health in the informal sector during the COVID-19 pandemic.International Journal of Health Sciences, 5(3), 416-428. https://doi.org/10.53730/ijhs.v5n3.1746

Tejedor, J.M. (2021). Vaccination and development in times of COVID-19. Finance and Economic Policy Magazine. 13(1).

Tobacco, T. C. P. G. T. (2008). A clinical practice guideline for treating tobacco use and dependence: 2008 update: a US public health service report. American journal of preventive medicine, 35(2), 158-176. https://doi.org/10.1016/j.amepre.2008.04.009

Uehara, T., Kawashima, Y., Goto, M., Tasaki, S. I., \& Someya, T. (2001). Psychoeducation for the families of patients with eating disorders and changes in expressed emotion: A preliminary study. Comprehensive psychiatry, 42(2), 132-138. https://doi.org/10.1053/comp.2001.21215

Urinov, M., Alikulova, N., Zukhritdinova, D., Usmonov, M., \& Urinov, R. (2021). Clinical, laboratory and instrumental indicators in patients who have suffered COVID-19. International Journal of Health Sciences, 5(3), 403-415. https://doi.org/10.53730/ijhs.v5n3.1719

Widjaja, G., Zahari MS, M., Hastuti, P., Nugraha, A.R., \& Kusumawaty, I. (2021). Understanding the COVID-19 Vaccination Program Among the Indonesian Public: A Challenge and a Hope for the Government.International Journal of Health Sciences, 5(3), 212-223. https://doi.org/10.53730/ijhs.v5n3.1429

Zulfa, S. Z, Emilia, O., \& Hidayat, A. (2021). Preparing midwives to provide birthing services in the independent midwifery practice during the COVID-19 pandemic. International Journal of Health Sciences, 5(3), 344-351. https://doi.org/10.53730/ijhs.v5n3.1554 


\section{Biography of Editors}

\begin{tabular}{|c|c|}
\hline & $\begin{array}{l}\text { I Wayan Suryasa (Founder and Managing Editor) } \\
\text { He received the Doctorate of Linguistics from Udayana University specializing in } \\
\text { the area of translation studies and semantics. He teaches translation, semantics at } \\
\text { the college level, as well as a consultant of publications in Indonesia and Ecuador. } \\
\text { His publications focus on translation studies, semantics related to the linguistics } \\
\text { field. He is active in his local area of Indonesia running a teacher research group } \\
\text { and organizing workshops. He is also Ass. Professor. } \\
\text { Email: iwayansuryasa@utm.edu.ec }\end{array}$ \\
\hline & $\begin{array}{l}\text { María Rodríguez Gámez (Chief Executive Editor) } \\
\text { She is the Professor and Researcher the Universidad Técnica de Manabí, } \\
\text { Portoviejo, Ecuador. Bachelor's in education, Specialization: Physics and } \\
\text { Astronomy, Master in Spatial Planning and Development in Renewable Sources of } \\
\text { Energy, Doctor of the Strategies and Planning of the Territory Program in } \\
\text { Renewable Energy Sources in the Pablo De Olavide University, Seville, Spain, PhD } \\
\text { in Geographical Sciences. National Commission of Scientific Degree in the } \\
\text { República de Cuba. } \\
\text { Email: maria.rodriguez@utm.edu.ec }\end{array}$ \\
\hline & $\begin{array}{l}\text { Tihnov Koldoris (Editor) } \\
\text { He is a professor at Queen Mary University of London, London, United Kingdom. It } \\
\text { is a public research university in London, England, and a constituent college of the } \\
\text { federal University of London. It dates back to the foundation of London Hospital } \\
\text { Medical College in 1785. He really interested in medical sciences and health } \\
\text { sciences. } \\
\text { Email: ijhms@sloap.org }\end{array}$ \\
\hline
\end{tabular}

Suryasa, I. W., Rodríguez-Gámez, M., \& Koldoris, T. (2021). Get vaccinated when it is your turn and follow the local guidelines. International Journal of Health Sciences, 5(3). https://doi.org/10.53730/ijhs.v5n3.2938 